\title{
SHOPPING CENTER: \\ CONSUMO, SIMULAÇÃO E CONTROLE SOCIAL
}

EDA GóES ${ }^{1}$

\begin{abstract}
RESUMO - O consumo mudou de intensidade, conteúdo e status, conformando o mundo e se associando aos processos de diferenciação. Partindo deste pressuposto, mas sem desconsiderar problemas decorrentes, como a alienação, sobre a produção do espaço urbano, entendemos que os shopping centers são espaços estratégicos para o entendimento desses processos nas cidades médias brasileiras. A perspectiva de análise é a do cotidiano, com atenção às práticas espaciais dos diferentes frequentadores, em sua relação com a atuação dos agentes produtores dos shopping centers, o que implica levar em conta as dimensões simbólicas, tanto do consumo (conduta ativa e coletiva, sistema de valores, função de integração e de controle social), quanto destes espaços, supostamente convertidos em espaços públicos contemporâneos, o que se relaciona diretamente com a sua capacidade de exercer um férreo controle interno, sem deixar de proporcionar sensação de liberdade e assim, também, aos limites dessas simulações.
\end{abstract}

Palavras-chave: Shopping center; consumo; controle social; produção do espaço urbano.

ABSTRACT - SHOPPING MALl: CONSUMPTION, SimULATION AND SOCIAL CONTROL. Consumption has changed in intensity, content and status, making the world conform to it, and associating itself with differentiation processes. We start from this presupposition without ignoring the problems it causes, like alienation. We see shopping malls as strategic to understanding the production of urban spaces in Brazilian middle-sized cities. Our perspective of analysis is that of the everyday, with attention to special practices of different users, and their relations with the producing agents of shopping malls. This implies taking into consideration the symbolic dimensions of consumption (active and collective behavior, system of values, roles of integration and of social control), as well as of shopping malls, supposedly converted into contemporary public spaces. This is directly related with the capacity of shopping malls to habour a strong social control in their interiors, while still producing the sensation of freedom.

Keywords: Shopping mall; consumption; social control; production of urban space.

Recebido: Junho 2015. Aceite: Fevereiro 2016.

1 Professora da Universidade Estadual Paulista (UNESP), Faculdade de Ciências e Tecnologia (FCT), Departamento de Geografia, 19060-900, Rua Roberto Simonsen, 305, Presidente Prudente, São Paulo, Brasil. E-mail: edagoes@fct.unesp.br 
RÉSUMÉ - LE CENTRE COMMERCIAL: CONSOMMATION, SIMUlation ET CONTROLE SOCIAL. Comme les autres processus de différenciation qui modèlent le monde, la consommation a changé d'intensité, de contenu et de statuts. Sans oublier les autres aspects de la production de l'espace urbain, nous pensons que les Centres commerciaux sont des espaces privilégiés pour étudier l’action de ces processus dans les villes moyennes du Brésil. On y a analysé la pratique quotidienne de divers clients, mise en rapport avec l'action des agents producteurs, en prenant en compte la dimension symbolique de la consommation et des espaces considérés, apparemment convertis en espaces publics donnant une sensation de liberté alors qu'ils résultent d'un implacable contrôle interne.

Mots clés : Centre commercial; consommation; contrôle social; production d'espace urbain.

\section{INTRODUÇÃO}

Neste artigo, o consumo é considerado como o meio a partir do qual as práticas espaciais e as lógicas econômicas podem ser apreendidas na atualidadei. O ponto de vista que justifica tal opção está fortemente apoiado na ideia de Bourdin (2005), para quem o consumo $^{\text {ii }}$ mudou de intensidade e conteúdo, bem como de status, conformando o mundo e se associando à tendência de individualização da experiência e aos processos de diferenciação. Nesta linha de interpretação, autores, como Baudrillard (1991), Lipovetsky (2007) e Bauman (2008) consideram que vivemos numa "sociedade do consumo", sem deixar de levar em conta as intrínsecas relações entre produção e consumo e os problemas decorrentes de tal constatação, sobretudo, em função da alienação que implica.

Com base nestes pressupostos e particularmente nos inúmeros desdobramentos contemporâneos do segundo pressuposto, a alienação, sobre a produção do espaço urbano, voltamos nossa atenção para os shopping centers, escolhidos como espaços estratégicos para o entendimento desses processos nas seis cidades médias brasileiras pesquisadas ${ }^{\text {iii }}$. No final esperamos ter demonstrado que os shopping centers podem ser considerados como sínteses das contradições urbanas contemporâneas, com base nas características gerais identificadas.

A perspectiva de análise adotada é a das práticas espaciais dos diferentes frequentadores dos shopping centers escolhidos para a pesquisa empírica, consumidores e trabalhadores (também consumidores), sem deixar de levar em conta a atuação de agentes como a empresa responsável pela incorporação e administração, os lojistas e o poder público municipaliv, a quem cabe a autorização para implantação e fiscalização posterior, e que, frequentemente, está, direta ou indiretamente, envolvido no estímulo da mesmav. Este último aspecto deve ser entendido à luz das relações simbólicas entre shopping center e "cidade moderna", na qual os moradores das cidades médias anseiam integrar-se.

Outras dimensões do consumo são importantes nesta pesquisa, já que "o consumo surge como conduta ativa e coletiva, como coação e moral, como instituição. Compõe todo um sistema de valores, com tudo o que este termo implica enquanto função de integração do grupo e de controle social" (Baudrillard, 1991: 95). Este controle torna-se bem 
evidente nos shopping centers, inseridos por Caldeira (2000) no âmbito dos "enclaves fortificados", que não se referem apenas a espaços residenciais, mas também a espaços comerciais, que estão na base da "cidade de muros", caracterizada pela autora.

Mas é preciso considerar que, para Baudrillard (1991), conformidade não é sinônimo de homogeneização do grupo, mas [sim] o fato de terem em comum o mesmo código, de compartilharem os mesmos signos que os diferenciam globalmente de outros grupos. As mudanças decorrentes estão diretamente relacionadas com a capacidade atribuída ao shopping center de gerar desejos, através de imagens, garantindo apenas satisfação parcial via consumo, mas ampla satisfação via acesso visual (ver e ser visto), como um desejo dirigido, aparentemente sem tensão, e pela participação de diferentes grupos de frequentadores, incluindo aqueles que podem efetivamente consumir suas mercadorias e os que se limitam a consumos mínimos (Sarlo, 2009) ou à simples fruição coletiva do espaço (Freitas, 1996; Cachinho, 2006). Trata-se de uma das simulações que caracterizam esse espaço, cujos limites foram evidenciados na sequência de episódios denominados "rolêzinhos", que foi a denominação dada às práticas coletivas de grandes grupos de jovens em shopping centers da periferia de São Paulo, ocorridos em dezembro de 2013 e janeiro de 2014. Os "rolêzinhos" geraram forte reação da Justiça, da polícia, da mídia (nacional e internacional) e dos administradores desses empreendimentos, como é exemplar o caso dos cartazes onde se lia "Grupos com mais de cinco pessoas podem ser solicitados a dispersarem-se em grupos menores", afixados nos corredores do Plaza Avenida Shopping de São José do Rio Preto, em janeiro de 2014.

Outra simulação é a suposta conversão do shopping center na praça pública contemporânea (Sarlo, 2009), vivenciada cotidianamente pelos jovens participantes dos "rolêzinhos". Quando levamos em conta que a dicotomia público-privado é estruturante das práticas espaciais na cidade contemporânea, tanto pela separação entre as dimensões pública e privada da vida humana, quanto do ponto de vista produtivo, distinguindo diferentes modos de intervenção urbana, pautados em lógicas próprias, de promoção pública ou de iniciativa privada, compreendemos que os processos atuais que tendem a diluir fronteiras (global-local, rural-urbano), entre as quais, público-privado, tanto quanto a erigir outras, como aquelas que inibem o acesso de alguns a espaços privados de acesso coletivo, como são os shopping centers, estabelecem regras diferenciadas para controle de visitantes e trabalhadores em condomínios fechados, etc. (conforme demonstrado por Sposito \& Góes, 2013). Esses processos demandam pesquisas sobre as tensões deles resultantes. No caso dos "rolêzinhos", mais uma vez, os limites da simulação e os problemas inerentes ao referido processo de diluição de fronteiras foram revelados, tanto nas manifestações protagonizadas pelos jovens das periferias, como nas reações desencadeadas.

\section{A DIMENSÃO ESPACIAL E A DIALÉTICA ENTRE HOMOGENEIDADE E HETEROGENEIDADE}

Partindo da assertiva de Garrefa (2011) de que os shopping centers são capazes de "criar localizações", o que demonstra sua flexibilidade, ao mesmo tempo em que a importância da localização é sempre levada em conta, observamos que, em Presidente Pru- 
dente, o Parque Shopping ${ }^{\text {vi }}$ caracteriza-se por estar próximo ao centro tradicional da cidade e inclusive da estação rodoviária. O Prudenshopping vii caracteriza-se por estar entre duas avenidas principais da cidade, sendo que a primeira dá acesso direto à Rodovia Raposo Tavares, além de estar próximo ao Parque do Povo, maior espaço público e área de lazer da cidade.

Em Marília, o Marília Shopping ${ }^{\text {viii }}$ situa-se na zona norte, próximo a três rodovias, enquanto o Esmeralda Shopping ${ }^{\mathrm{ix}}$ situa-se na avenida do mesmo nome, na zona sul, próximo a loteamentos e condomínios fechados, além de outros estabelecimentos comerciais voltados ao consumo dos segmentos de alta renda.

Em São Carlos, há um único shopping, o Iguatemix. A sua localização, em área nobre, ao lado do Hotel Ibis (Rede Accor) e de espaços residenciais fechados, horizontais e verticais, assemelha-se, guardadas as diferenças entre as realidades urbanas, inclusive de tamanho populacional, com o Iguatemi Ribeirão ${ }^{\mathrm{xi}}$, localizado em área conhecida como Vila do Golf, ainda mais sofisticado, o que também ocorre com o perfil e o público alvo desse shopping, comparativamente ao de São Carlos. Tais localizações podem ser visualizadas na figura 1.

As conexões rodoviárias podem ser um critério importante para a localização, como ocorre em Presidente Prudente ${ }^{\mathrm{xii}}$, com cidades polarizadas por ela, o que garante ao Prudenshopping um alcance maior em termos da atração de consumidores de outras cidades, embora esses critérios não estejam ausentes no Parque Shopping. Mas a valorização dessas conexões não é regra, embora seja evidente a intensificação das conexões no âmbito da rede urbana, pela capacidade de atração, ainda que desigual, dos shopping centers implantados em cidades médias. Além dessas conexões rodoviárias, as conexões simbólicas simuladas por franquias como McDonald's, e marcas, como Nike, por exemplo, entre seus consumidores, também são estratégicas. Elas possibilitam a construção identitária de um grande grupo que, portanto, se diferencia dos outros, não conectados, ausentes dos shopping centers. Isso ocorre, mesmo que a homogeneidade também se imponha, ou seja, há uma relação dialética e contraditória entre homogeneidade e heterogeneidade.

O público alvo dos shopping centers pesquisados são as classes médias, o que poderia ser entendido como expressão de homogeneização e corrobora o que também foi observado por Sarlo (2009: 33), para quem "el shopping es un paraíso de capas medias". A partir de observações gerais, consideramos que, por um lado, nas realidades metropolitanas brasileiras, está em curso um processo acelerado de segmentação dos shopping centers em públicos alvos específicos, selecionados por renda, ou seja, em São Paulo, por exemplo, há shopping centers voltados aos segmentos de alta renda, enquanto outros são voltados aos segmentos populares. Por outro lado, nas cidades médias, consumidores das classes médias continuam a ser indispensáveis a todos eles, como a presença das mesmas lojas âncoras (C\&A, por exemplo) e fast foods (McDonald's, por exemplo) confirma, mesmo que se acentue a segmentação do público alvo de cada shopping, sugerida pela inauguração do Shopping Cidade Norte (2012), explicitamente popular, e do Iguatemi (2013), voltado a segmentos elitizados, ambos em São José do Rio Preto, assim como, pela inauguração do Londrina Norte Shopping (2012) e do Boulevard Londrina Shopping (2013), respectivamente, voltado as segmentos populares e elitizados, em Londrina. 

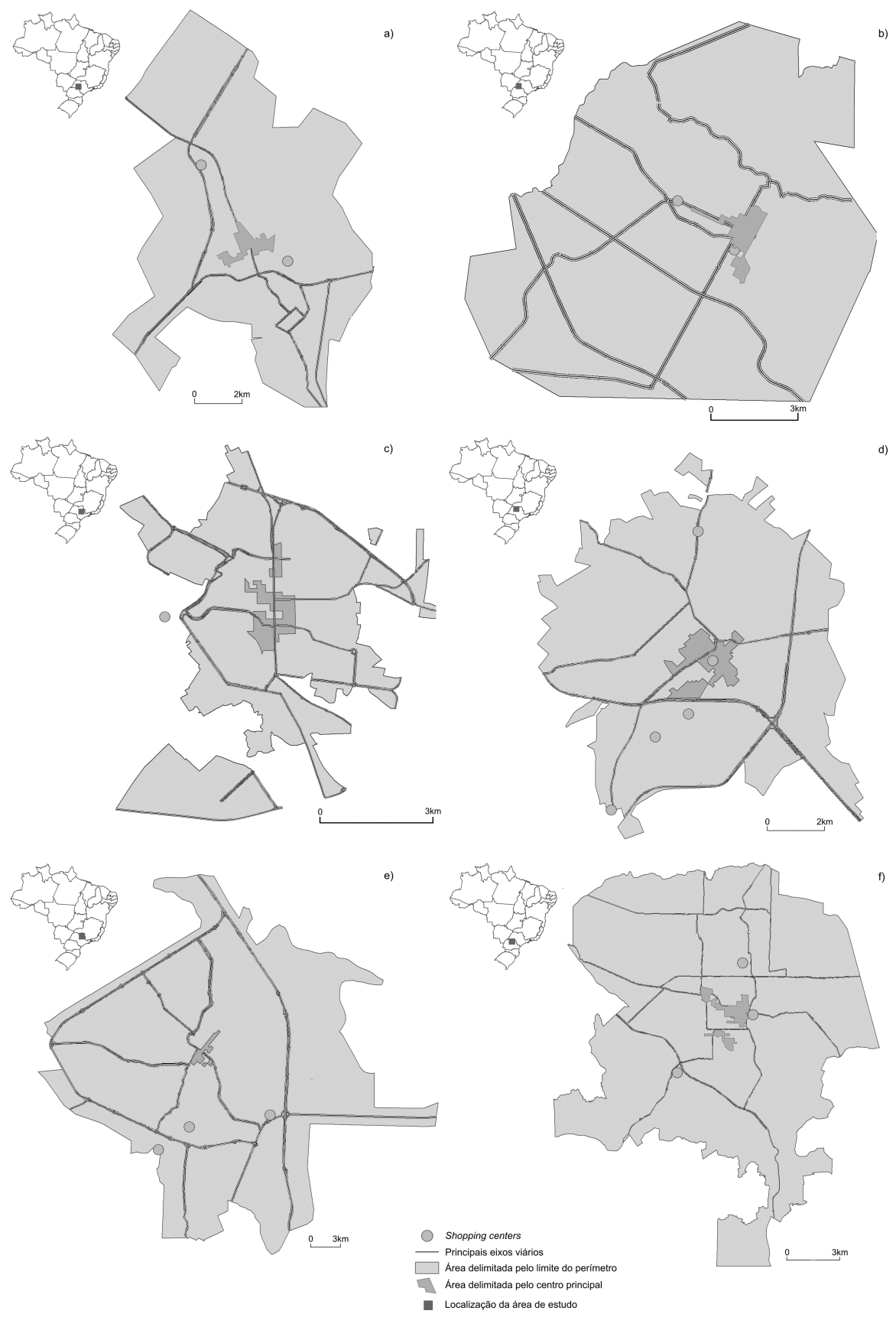

Fig. 1 - Shopping centers nas cidades médias pesquisadas, 2014.

Fig. 1 - Shopping malls in medium-sized cities surveyed, 2014.

a) Marília; b) Presidente Prudente; c) São Carlos; d) São José do Rio Preto; e) Ribeirão Preto; f) Londrina 
Mas diferenças foram observadas entre os dois shopping centers cujo cotidiano acompanhamos mais detidamente, Prudenshopping e Parque Shopping, em Presidente Prudente, indicando que há relações contraditórias entre homogeneidade e heterogeneidade no cotidiano desses espaços. No caso do primeiro, os segmentos socioeconômicos de mais alto poder aquisitivo são o público alvo, o que se observa pelo destaque dado à presença de conhecidas grifes masculinas e femininas no seu site (Polo Play, Brooksfield, M. Officer, Forum, por exemplo). Esse direcionamento é favorecido pela localização do Prudenshopping, em especial pela maior proximidade dos espaços residenciais fechados de classes médias e altas, mas também pela proximidade com o Parque do Povo, maior área de lazer da cidade, e com os estabelecimentos voltados ao lazer noturno que se têm instalados ao longo das vias nas quais se situa. Por outro lado, no caso do Parque Shopping, a referência às duas lojas âncoras, Americanas e Supermercado Mufatto, sugere que seu foco recai nos segmentos socioeconômicos de renda menos elevada que o primeiro, o que também é favorecido pelo entorno, não apenas no que se refere ao bairro no qual está localizado, Vila Nova, mas inclusive à proximidade de inúmeros espaços de trabalho e serviços, como Fórum, Santa Casa, Poupa Tempo, clínicas médicas, INSS, além do Terminal Rodoviário. Trata-se, portanto, de mais uma decorrência da localização, ainda que não exclusivamente dela. As observações que fizemos sobre o perfil dos frequentadores e sobre os horários de maior movimento nos levaram a identificar o público principal do Parque Shopping como de trabalhadores, nos termos propostos por Souza (2012) xiii. $^{\text {. }}$

Quando atentamos para o entorno de cada um desses dois shopping centers, além das diferenças já comentadas, há evidente prioridade dos veículos (carros e motos) no caso do Prudenshopping, o que foi reforçado depois da sua ampliação, quando empenas cegas, apenas interrompidos por entradas de caminhões de carga, ampliaram a caracterização de uma fachada fechada e impermeável e seu impacto sobre a Avenida Washington Luiz, uma das mais importantes da cidade, que passou a ser evitada pelos pedestres nesse trecho ${ }^{\text {xiv }}$. O mesmo pode ser observado no caso do Shopping Iguatemi, em São Carlos, mas há situações em que a localização próxima de uma rodovia (Marília Shopping, por exemplo) e a desconexão relativa com os demais espaços urbanos, torna a dependência de carros e motos mais evidente, embora a presença (ou não), além da frequência, de linhas de ônibus, seja sempre importante ${ }^{\mathrm{xv}}$.

No Parque Shopping, observamos uma relação mais direta com o entorno imediato, ainda que exclusivamente na sua entrada principal. A abertura direta para a rua, a inauguração do Café Jopanna's (2013), a pequena presença de câmeras e de agentes de segurança e a maior informalidade na atuação desses agentes, são elementos que proporcionam ao local um caráter de "espaço de transição" (Gehl, 2013), o que o torna mais convidativo à permanência e não apenas a sua utilização como espaço de passagem, além de ser mais permeável (fig. 2). Mas não se pode desconsiderar que a maior parte dos frequentadores chega ao Parque Shopping de carro ou moto ${ }^{\text {xi }}$, o que se faz pelas entradas diretamente ligadas aos estacionamentos, e que as fachadas desse shopping mantêm a mesma característica identificada em todos os shopping center pesquisados, são empenas cegas, evitando portanto qualquer comunicação com o entorno, qualquer permeabilidade. 

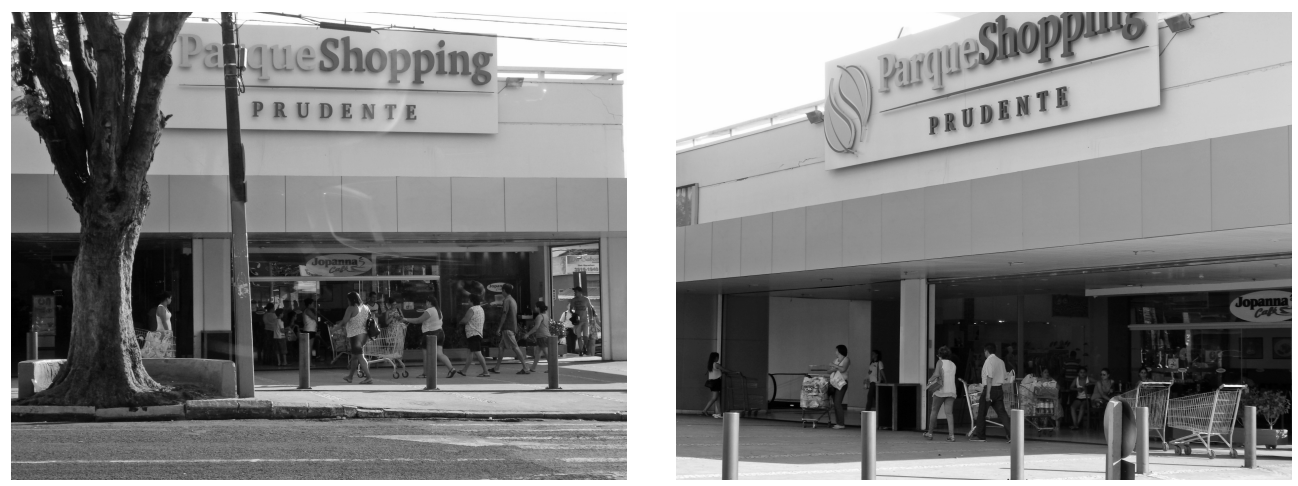

Fig. 2 - Parque Shopping e Jopanna's Café - Presidente Prudente, 2015.

Fig. 2 - Parque Shopping e Jopanna's Café - Presidente Prudente, 2015.

A dimensão temporal é fundamental, uma vez que tratamos de processos e não de fatos novos, isolados e repentinos. No caso de Presidente Prudente, a instalação das Lojas Americanas, em 1988, que deu origem ao primeiro shopping center da cidade, Shopping Center Americanas, foi marco inicial de um processo desencadeado com amplo apoio do poder público municipal e dos prudentinos de modo geral, que vincularam fortemente esses novos espaços comerciais ao imaginário da cidade moderna a que desejavam se incorporar.

São espaços que prezam a previsibilidade, mas grandes rupturas, decorrentes de reformas e, sobretudo, de ampliações, cada vez mais frequentes ${ }^{\text {xvii }}$. Os dois shopping centers de Presidente Prudente estiveram em obras nos últimos anos e, depois da última ampliação e reforma, vistosos lustres de cristal passaram a ser vistos no interior das lojas do Parque Shopping também. A partir da reforma, algumas das diferenças entre este e o Prudenshopping foram amenizadas, embora a nova ala inaugurada no Prudenshopping em 2013 explicite novos esforços de diferenciação ${ }^{\text {xviii }}$, tanto entre shopping centers, como no interior do mesmo, ainda que de forma menos marcante ${ }^{\mathrm{xix}}$.

Estes aspectos, além de confirmarem a busca constante de novos signos de diferenciação, com os quais certos grupos se identifiquem (e não outros, mas em função dos outros) e o prestígio social reificado a eles associado (Baudrillard, 1991), indicam a necessidade de se problematizar as relações entre interior e exterior destes espaços, mesmo que as impermeabilidades e permeabilidades comentadas anteriormente estejam presentes. Neste sentido, reiteramos a identificação dos principais consumidores do Parque Shopping como trabalhadores, nos termos propostos por Souza (2012), e a importância das mudanças relacionadas à expansão da renda e do crédito (Neri, 2012), responsáveis pela ampliação do consumo ${ }^{\mathrm{xx}}$ desse segmento, como aspectos relevantes para compreensão do processo de diferenciação, cujos impactos sobre as cidades médias pesquisadas são significativos e exigem mais atenção.

Outros frequentadores assíduos dos shopping centers são os jovens, cujas práticas criaram "espaços de transição" em alguns deles, como ocorre num dos estacionamentos do Prudenshopping, trasformado em espaço de encontro, num movimento que mescla 
reprodução das relações de consumo e lazer projetadas pelo shopping, previsíveis, portanto, com outras menos previsíveis e controladas. As primeiras decorrem da presença de grandes franquias que recorrem intensamente ao marketing com forte apelo visual, dirigindo-se a quem está dentro e fora deste espaço, ultrapassando, portanto, seus limites. Tanto quando consideramos a escala dos veículos, quanto a escala dos pedestres, suas placas chamam sempre atenção, tornando-se importantes símbolos urbanos e ajudando a criar uma "arquitetura de persuasão" (Venturi, 1968).

Dentre as outras práticas espaciais juvenis, menos previsíveis, observamos o namoro sob o escurinho protetor de uma das poucas árvores, a transformação de floreiras em bancos e os grandes agrupamentos de jovens próximos da placa "Proibido aglomerações", colocada na entrada do Prudenshopping, justamente às sextas à noite. Será essa prática espacial tão visível, tolerável porque não ocorre no interior do shopping e sim nesse espaço de transição, tendo, portanto, impacto limitado sobre a representação de controle e segurança desses espaços? É provável que a resposta deva levar em conta um processo mais amplo, no qual os jovens da periferia são protagonistas, tanto nas cidades médias, quanto nas metrópoles, e que relaciona práticas toleráveis com práticas intoleráveis, como foi o caso dos "rolêzinhos" e como é reiterado na observação feita por uma ex-vendedora da "He Calçados" do Prudenshopping: "víamos um perfil muito diferenciado do esperado do shopping no horário da sexta à noite e sábado à noite, que comprometia as vendas"xxi (Entrevista realizada em 13/09/2013).

Entrevista com a Gerente de Marketing do Shopping Iguatemi de São Carlos indicou semelhanças, relacionadas com a proximidade de áreas públicas ${ }^{x x i}$, mas diferenças em relação à possibilidade dos estacionamentos serem transformados em espaços de transição. Nesta, a ambiguidade com que é vista a presença do "público jovem" também é ressaltada:

"O público jovem vem de quarta-feira, sábado e domingo. Porém, sexta-feira, menos. Nós temos um problema, temos uma praça aqui na frente do Hotel Ibis, aqui no entorno, e quando abrimos o shopping, tinha boate aqui dentro, na verdade, era restaurante que durante a noite tornava-se uma casa noturna, que chamava 'Café Cancun'. Isso para nós foi um 'tiro no pé, nós teríamos que deixar o shopping aberto até 3 ou 4 horas da manhã, operando com o risco de todas as outras lojas fecharem e um público que vem para beber, para balada e pode ocorrer briga, polícia... Essa imagem é muito difícil de nós mudarmos, porque o público jovem vem para cá, compra bebida no [Supermercado] Extra e fica bebendo na praça e entra no shopping. Nós fazemos um trabalho muito forte para tentar mudar esse público. Não é um público jovem que não queremos e sim esse tipo de público jovem que vem para balada. Não é porque ele não consome, é porque ele 'causa"'. $x$ xiii

Assim confirmamos que, embora a homogeneidade seja almejada pelos shopping centers, há variações, embora sempre menores que as presentes em outros espaços coletivos da cidade, especialmente os espaços públicos. No caso das cidades médias, as distâncias menores são fator a ser levado em conta quando os processos de diferenciação revelam seus limites, sobretudo, se contrapostas às distâncias muito maiores e às condições de uso dos transportes coletivos das áreas metropolitanas, marcadas pela superlotação, lentidão do trânsito etc. 


\section{A DIMENSÃO TEMPORAL, A INSEGURANÇA URBANA E NOVAS FORMAS DE CONTROLE SOCIAL}

Tanto a origem dos shopping centers nos EUA, no contexto do processo de suburbanização do pós-guerra, quanto a influência exercida sobre o Brasil, na incorporação de tal modelo, são amplamente reconhecidas (Vargas, 2001; Muller, 2004; Rifkin, 2009; Pérez, Salcedo \& Cáceres, 2012), no entanto, os contextos diferentes precisam ser levados em conta. O Shopping Iguatemi, na capital paulista, foi o pioneiro, inaugurado em 1966, mas o desenvolvimento desses empreendimentos apenas ganha impulso nos anos 1980 (Garrefa, 2011; Padilha, 2006; Pintaudi, 1992). Desse modo, a atenção à dimensão temporal favorece a identificação de formas semelhantes, com diferenças em seus conteúdos, aí incluídos os frequentadores desses empreendimentos.

No contexto dos anos 1980, além das mudanças demográficas e econômicas ressaltadas por Pintaudi (1992) e Padilha (2006), importantes para a compreensão do contexto no qual a expansão dos shopping centers se dá, também precisam ser levados em conta, a crise econômica dos anos 1980 e suas relações com as mudanças políticas que estavam em curso, como a redemocratização, cujos desdobramentos, segundo Caldeira (2000), teriam gerado reação nas classes médias, que buscaram demarcar novas diferenças, em função da igualdade de direitos propugnada pela Constituição de 1988. Nessa reação, o processo de fragmentação socioespacial foi impulsionado nas cidades brasileiras, com a implantação de espaços residenciais fechados e shopping centers.

Em tal processo, a insegurança emerge como problema urbano cada vez mais central. Mas é fundamental compreender que esse processo não se limita às realidades metropolitanas, sendo por isso significativa a inauguração do Ribeirão Shopping, em $1981^{\text {xxiv }}$. Mas a dimensão do controle social sempre foi importante nos shopping centers brasileiros, tendo sido atualizada e aperfeiçoada consoante os avanços tecnológicos. Ocorreu também, no âmbito do mesmo processo, um esforço de segmentação do mercado consumidor, por renda. Três aspectos diferentes sustentam tal constatação: a) a observação de Garrefa (2004) sobre a matéria "Shopping tem recorde de visitas" xxv , com base na qual, afirma que "tal fato - apesar dos jornais noticiarem como sucesso de lotação do Shopping - não foi avaliado como positivo, pois atrapalhava as vendas"; b) a entrevista realizada com o administrador do Esmeralda Shopping (Marília), quando afirma que "nosso público consumidor é bem classe média alta, classe A.[...] O nosso público é mais segmentado, principalmente por conta da área onde nos localizamos"xxvi, e c) a recente inauguração de shopping centers voltados a segmentos de classe média e elite, como o Iguatemi Ribeirão ${ }^{\text {xxvii }}$ o Boulevard Londrina Shopping ${ }^{\text {xxviii }}$ e o Iguatemi São José do Rio Preto ${ }^{\text {xxix }}$, em São José do Rio Preto.

Outros aspectos, observados nas cidades de Ribeirão Preto e São José do Rio Preto reiteram, ao mesmo tempo que introduzem, a tendência para a segmentação. Na primeira cidade, a par da matéria "Iguatemi abre com promoções"xxx na qual o público alvo do shopping é repetidas vezes identificado como de classe média e alta, foi publicada uma notícia menor, "Buriti Shopping deve abrir as portas em 2015", que informa: "Cerca de 200 lojas e Área Bruta Locável de $32000 \mathrm{~m}^{2}$ e investimentos de $\mathrm{R} \$ 300$ milhões $^{\mathrm{xxxi}}$, o shopping visa atender a classe média e baixa da região central e norte de Ribeirão". Além das 
diferenças evidenciadas na comparação com as informações sobre o Iguatemi, como a área bruta locável de $44100 \mathrm{~m}^{2}$, também a localização do Buriti, em área próxima ao centro tradicional, ganha mais significado, quando contraposta à localização "privilegiada" do Iguatemi, a que já fizemos referência.

Reconhecemos, assim, um duplo processo de fragmentação socioespacial, no qual os shopping centers desempenham papel importante no reconhecimento da ampliação da capacidade de consumo dos segmentos populares, ambos intensificados a partir dos anos 1990. É nesse sentido que aponta a inauguração, já mencionada, do Shopping Cidade Norte, em São José do Rio Preto, localizado na zona norte, amplamente caracterizada como popular, contrapondo-se a outra, a zona sul, cada vez mais elitizada, na qual já estão o Rio Preto Shopping e o Iguatemi; assim como do Londrina Norte Shopping (2012) e do Boulevard Londrina Shopping (2013).

Assim vão se configurando as especificidades adquiridas pelos shopping centers no Brasil $^{\text {xxxii }}$, mesmo que a atenção aos estudos de caso possibilite a identificação de outras particularidades próprias das escalas mais reduzidas, inclusive, das microescalas do cotidiano. Trata-se, portanto, de tendência à homogeneização, numa escala global, do way of life dos EUA, via incorporação do modelo shopping center, conforme reafirma o seguinte depoimento dado por um vendedor do quiosque das Havaianas, do Prudenshopping:

"O público aqui do shopping eu acho muito igual, muito igual, muito uniforme, as mulheres são todas iguais, os homens são todos iguais, os casais todos iguais, as crianças todas vão na mesma escola, nada de diferente." (Entrevista realizada em 28/10/2013).

Mas, simultaneamente, se trata de tendência à produção de conteúdos e, sobretudo, de seus desdobramentos, que guardam diferenças. São heterogêneos especialmente no que se refere aos impactos urbanos, sociais e políticos. Assim chegamos à importância adquirida pela dimensão do controle social, que sempre esteve presente nesses espaços, mas cuja relevância cresce nas últimas décadas. Há outros desdobramentos, no entanto, como a naturalização dos mecanismos e práticas de controle social, não apenas nestes espaços, mas a partir deles, bem como a contraposição a uma suposta eficiência do mercado para dar resposta a problemas que o Estado não se tem mostrado capaz, como é o caso da insegurançaxxiii. Mais uma vez, as implicações de natureza política vão muito além do shopping center, impactando a produção do espaço urbano.

Para caracterizar a atuação concreta dos shopping centers no que se refere ao controle dos seus espaços e partindo do pressuposto de que eles são "una organización férrea que parece libre y algodonosa" (Sarlo, 2009: 24), dois principais procedimentos metodológicos foram utilizados: a) a elaboração de plantas com a localização dos estabelecimentos comerciais, demais espaços internos e sistemas de segurança; e b) a elaboração de croquis com os principais percursos dos frequentadores no interior de cada shopping.

$\mathrm{Da}$ análise das plantas e croquis, no que se refere aos equipamentos de segurança, importa realçar que o Parque Shopping não possui câmeras de segurança em sua entrada principal de pedestres. No total, foram encontrados 13 câmeras de segurança no andar térreo e 3 no subsolo ${ }^{\text {xxiv }}$. No entanto, o Prudenshopping possui dois modelos de câmeras de segurança, um em que a câmera aponta para o local que está sendo filmado e outro no 
qual há proteção redonda e preta, que impossibilita a identificação da sua direção, mas permite que uma área mais ampla seja filmada. Este possui um total de 50 câmeras, distribuídas entre as entradas e a parte interna, com evidente direcionamento para as primeiras: são 27 câmeras num piso e 23 no outroxxxv.

Nossa hipótese é que a presença destes equipamentos e serviços de segurança atua em dois sentidos principais, além daqueles que são mais evidentes e, portanto, atraentes para os frequentadores. Primeiro, a mediação dos sistemas de segurança ${ }^{\mathrm{xxvy}}$ estabelece limites estreitos para os contatos entre diferentes citadinos, buscando tornar desnecessárias as evitações, embora elas acabem por se manifestar na predominância dos diferentes segmentos sociais, em termos dos dias e horários de frequência. Assim, por exemplo, jovens da periferia são esperados nas sextas à noite, quando não virão jovens de classe média; homens e mulheres trabalhadores são esperados de segunda a quinta, no período noturno; por sua vez famílias com crianças vêm principalmente aos sábados, domingos e feriados. Essas lógicas, assim como a mediação dos sistemas de segurança, limitam a produção de um esfera pública nos espaços coletivos dos shopping centers, podendo chegar a sua neutralização, justamente pela limitação dos contatos entre diferentes citadinos.

O segundo sentido diz respeito à homogeneização, uma vez que, aparentemente, todos os frequentadores, incluindo-se os trabalhadores do shopping, têm em comum o mesmo código, compartilham os mesmos signos que os diferenciam globalmente de outros grupos, encobrindo profundas desigualdades sociais e tensões a ela relacionadas, numa simulação cujos limites foram evidenciados pelos "rolêzinhos". Uma vendedora entrevistada expressou assim essa experiência: "Como consumidora, acaba sendo positiva [a experiência de trabalhar num shopping center] porque eu escolho as lojas, ou as lojas me escolhem, não sei..." (Entrevista realizada em 28/10/2013).

No que se refere aos percursos, durante as observações de campo, procuramos identificar os predominantes, levando em conta a relação que estabelecem com as lojas e sua localização, além dos outros equipamentos e serviços, conforme demonstra o exemplo da figura 3.

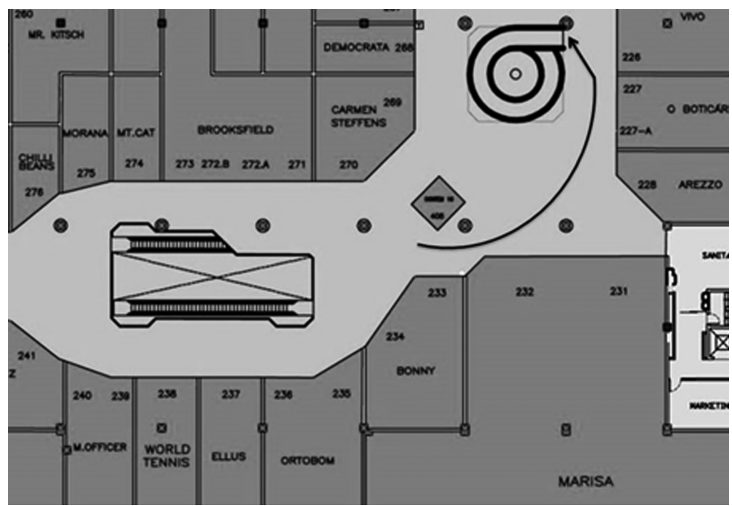

Fig. 3 - Percurso identificado no piso superior do Prudenshopping, 2013.

Fig. 3 - Route identified on the rooftop Prudenshopping, 2013. Realização: Ana Paula Zimiani Vicente (Bolsista I.C./FAPESP) 
Tais critérios partem do pressuposto que, num espaço controlado, pautado em lógicas do mercado, as lojas não foram dispostas de uma maneira aleatória e os percursos foram previstos (Goss, 1993), o que pôde ser constatado nos dois casos, pois, de uma maneira geral, analisando os percursos tanto do Prudenshopping, quanto do Parque Shopping, os deslocamentos levam os usuários a passar pelas lojas âncoras. Recorrem a um desejo dirigido e reforçam a ausência de casualidade (Sarlo, 2009), embora a ilusão de liberdade esteja presente. Novamente, sobre este aspecto, a entrevista com o superintendente do Parque Shopping (07/05/2013) foi reveladora. Para este, "o ideal, o conceito, o corretinho, é nenhuma loja estar por acaso do lado da outra", além disso, "tem até empresas que no planejamento já sabem quem vai ficar onde; têm projetos que são mais segmentados, o que é uma coisa bem moderna, bem americana, um planejamento de shopping mais maduro".

Tal nos leva a perceber que os percursos feitos no interior destes espaços, juntamente com a posição e conteúdos das vitrines, atuam estrategicamente na conquista do consumidor, quando vai ao shopping. Porém, não se deve esquecer que é possível ao indivíduo entregar-se somente ao "prazer ótico" (Sarlo, 2009: 26). Isso faz com que a relação dos citadinos com o shopping center se intensifique, porque neste espaço há uma sobreposição estratégica entre o real e o sonho, o imaginário e o cenário produzido, que utiliza a linguagem visual para seduzir o consumidor, simulando sua inclusão no mundo da mercadoria. Nessa estratégia, as repetições, a rotina nos percursos, são importantes. Novamente, as entrevistas com vendedores foram significativas, como ilustra o seguinte exemplo:

\footnotetext{
"Quando você trabalha em um shopping, você conhece tudo, passo a passo, você sabe até a posição do manequim de cada loja, porque você está aqui dentro, não tem o que fazer. [...] E você sabe quando chega mercadoria, com a amizade que você cria com as outras lojas, eles acabam te dizendo - 'oh, vai chegar tal coisa, vai ter saldão, eu separo tal coisa pra vocề - então, como consumidora, é bom. E o salário vai embora...” (Entrevista realizada em 11/10/2013).
}

Na elaboração de plantas com identificação e localização dos estabelecimentos comerciais, atenção especial foi dada às franquias, como McDonald's, Subway, Pizza Hut, por sua notável capacidade de simular a inserção de cada um dos seus consumidores, particularmente dos jovens consumidores, numa rede, invisível e global, na qual desejam ser incluídos, sobretudo graças à astúcia da publicidade, que é capaz de "atingir cada qual em função dos outros, nas suas veleidades de prestígio social reificado" (Baudrillard, 1991). Esta ideia é confirmada pelo depoimento de um jovem sobre os "rolêzinhos": "um shopping era tudo que a gente poderia aspirar na vida. Com McDonald’s então... [...] Na periferia de São Paulo, consumir é glorioso" (Folha de S. Paulo, 19/01/2014, versão digital). Nessa passagem, a combinação estratégica entre shopping center e franquias como McDonald's é valorizada, mesmo que tais franquias também se localizem fora desses espaços.

Relacionados com a mesma estratégia, baseada na dialética entre ser e parecer, identificamos os mecanismos de controle empregados sobre os trabalhadores das lojas dos shopping centers. Exigências relacionadas com a aparência e ser jovem são requisitos combinados com proibições como: "na loja não poderia sentar durante o período de 
trabalho, tinha que ficar o tempo todo em pé" (Entrevista realizada em 13/09/2013). O mesmo ocorre com a abordagem de clientes no corredor ou próximo à vitrine da loja, havendo inclusive orientação no sentido de se evitar olhar diretamente para ele, antes da entrada, o que reafirma o controle exacerbado pelo qual gestos simples, como olhar, são dirigidos. Além disso, são simultaneamente trabalhadores e consumidores, especialmente da praça de alimentação, onde se alimentam diariamente, mas, com frequência, também dos demais estabelecimentos comerciais. Compartilham "o prazer de comprar", durante a jornada de trabalho, atendendo duplamente aos interesses do mercado, ao mesmo tempo em que ajudam a tornar mais suportáveis, porque menos evidentes, as diferenças historicamente reproduzidas na sociedade brasileira. Mas nem sempre esse cotidiano é aceite com tranquilidade, conforme comenta um dos trabalhadores entrevistados:

\footnotetext{
"Me irrita, eu acho uma caixa, me irrita, os outros vendedores não têm essa percepção, eles nem param para pensar, mas eu acho que a respiração é artificial, eu não sei quando chove, quando faz vento. [...] Sabe, eu não sei se está chovendo, então é seguro, até nisso é seguro, nesses fatores climáticos, acaba não passando frio, nem calor, tem a segurança do shopping, tem essas comodidades, mas me irrita bastante, é um mundo programado para ser bonitinho." (Entrevista realizada em 28/10/2013).
}

\section{CONCLUSÕES}

Consumo, simulação e controle social são algumas dimensões que se combinam na produção dos shopping centers nas cidades médias. Nessa tríade, a simulação desempenha papel estratégico que possibilita, inclusive, a suposta conversão do shopping center na praça pública contemporânea, numa simulação cujos limites e contradições foram evidenciados pelos "rolêzinhos" e pelas reações por eles desencadeadas, nas quais, a importância das diferentes lógicas que pautam espaços públicos e espaços privados foram explicitadas. Assim se reconhece que, ao mesmo tempo em que algumas fronteiras experimentam um processo de diluição, outras são erigidas e se multiplicam, indicando que a simulação influencia fortemente as representações sociais desses processos e dos espaços produzidos.

Tal influência está presente inclusive na bibliografia recente sobre os shopping centers e suas relações com os demais espaços urbanos. Sarlo (2009), por exemplo, neles identifica uma contraposição aos espaços públicos da cidade, baseada na suposta superioridade dos espaços privados. Nessa perspectiva, a característica homogeneidade que se refere à estética e à arquitetura, à rigidez do controle social e dos consumidores, se contrapõe à heterogeneidade própria da cidade. As relações entre controle social e consumo são reiteradas, uma vez que tudo o que dificulte a obtenção do lucro deve ser rejeitado, conforme mencionado por representante da Alshop (Associação Brasileira de Lojistas de Shopping), justificando as liminares obtidas contra os 'rolêzinhos', "eles assustam clientes e, consequentemente, prejudicam as vendas" (Folha de S. Paulo, 19/01/2014). 
Ainda que leve em conta entrevista feita com o diretor do Centre Comercial La Toison d'Or, de Dijon (França), na qual ele afirma que "o que é preciso compreender bem é que nosso negócio é econômico, não se trata de nos dar prazer associando lazer e comércio" (Padilha, 2006: 67), a reflexão de Padilha diferencia-se de Sarlo, inclusive quando procura incorporar as relações entre "violência" e produção do espaço urbano no Brasil. Para ela, os shopping se transformam em novas cidades (Padilha, 2006). Assim, também no âmbito da produção do conhecimento sobre as cidades brasileiras, passamos das imagens à realidade, sem mediações e, sobretudo, sem crítica e sem desvendar as contradições nas quais se pauta esse processo, até que a realidade se manifeste e nossas respostas sejam problematizadas, como aconteceu frente aos "rolêzinhos".

Além da estratégica combinação entre compras e lazer, o trabalho de Padilha oferece elementos importantes sobre o papel desempenhado pelos serviços nesses espaços, o que contribui para a compreensão das simulações acima referidas. Para essa autora, é a relevância crescente dos serviços que os caracteriza como "shopping center híbridos" (Padilha, 2006: 26), o que foi reiterado durante as entrevistas que fizemos com representantes das administrações de shopping centers.

No Shopping Iguatemi Ribeirão, novos aspectos relacionados aos serviços foram incorporados e devem merecer atenção nas pesquisas que estão em curso, como é o caso da inauguração de um posto de atendimento da Polícia Federal no seu interior, com o fechamento do posto que funcionava na Av. Presidente Kennedy, acompanhada do seguinte comentário do Secretário de Turismo do Município: "São pessoas que virão de cidades da região para Ribeirão. Além de impulsionar o turismo emissivo, também movimenta o turismo receptivo e gera consumo em Ribeirão" (A cidade, 30/09/2013).

Retomando o papel estruturador das distinções entre espaços públicos e privados nas cidades contemporâneas e reconhecendo as contradições inerentes aos processos que buscamos discutir neste artigo, nos quais os shopping centers são estratégicos, defrontamo-nos com os desafios colocados pelos limites das simulações das quais participamos cotidianamente.

\section{REFERÊNCIAS BIBLIOGRÁFICAS}

Baudrillard, J. (1991). A sociedade de consumo. Lisboa: Ed. 70 .

Bauman, Z. (2008). Vida para consumo. A transformação das pessoas em mercadoria. Rio de Janeiro: Zahar.

Bourdin, A. (2005). La métropole des individus. Paris: Éditions de l'Aube.

Cachinho, H. (2006). Consumactor: da condição do indivíduo na cidade pós-moderna. Finisterra Revista Portuguesa de Geografia, XLI (81), 33-56.

Caldeira, T. P. do R. (2000). Cidade de muros. São Paulo: Ed. 34 - Edusp.
Freitas, R. (1996). Centres commerciaux: îles urbaines de la postmodernité. L'Harmattan, Paris.

Garrefa, F. (2011). Shopping centers: de centro de abastecimento a produto de consumo. São Paulo: Senac.

Garrefa, F. (2004). O Ribeirão Shopping e suas quatro expansões: um retrato da evolução dos espaços e estratégias utilizadas pelo setor terciário. Anais do IV Seminário Internacional da LARES (Latin American Real Estate Society), São Paulo. 
Goss, J. (1993). The 'magic of the mall': na analysis of form, function and meaning in the contemporary retail built environment", Annals of the Association of American Geographers, 83 (1), 392-403.

Lipovetsky, G. (2007). A felicidade paradoxal. Ensaio sobre a sociedade do hiperconsumo. Lisboa: Edições 70 .

Muller, P. O. (2004). Transportation and urban form: stages in the spatial evolution of the American metropolis. In Hanson, S. \& Giuliano, G. (Eds.), The Geography Urban transportation. (pp. 59-85). New York: Guilford Press.

Neri, M. (2011). A nova classe média. São Paulo: Saraiva. Oliveira, F. (1999). Privatização do público, destituição da fala e anulação da política: o totalitarismo neoliberal. In Oliveira, F. \& Paoli, M. C. (Orgs.), Os sentidos da democracia. (pp. 55-81). Petrópolis: Vozes/Brasília: NEDIC.

Padilha, V. (2006). Shopping center: a catedral das mercadorias. São Paulo: Boitempo.
Perez, M., Salcedo, R. \& Cáceres, G. (2012). Apropiación y control social en un centro comercial de Santiago: prácticas socioespaciales y significaciones adolescentes. Eure, 113, 53-75.

Pintaudi, S. M. (1992). O templo da mercadoria. São Paulo: Editora UNESP.

Rifkin, J. (2000). La era del acceso. Barcelona: La revolución de la nueva economía. Paidós.

Sarlo, B. (2009). La ciudad vista. Buenos Aires: Siglo Veintiuno.

Sposito, M. E. B. (2007). Cidades médias: espaços em transição. São Paulo: Expressão Popular.

Sposito, M. E. B., \& Góes, E. M. (2013). Espaços fechados e cidades: insegurança urbana e fragmentação socioespacial. São Paulo: Editora UNESP.

Souza, J. (2010). Os batalhadores brasileiros. Belo Horizonte: Editora da UFMG.

Vargas, H. C. (2001). Espaço terciário. São Paulo: SENAC. Venturi, R. (2003). Aprendendo com Las Vegas. São Paulo: Cosac \& Naify.

i Por essa razão, o consumo foi eleito como importante para o Projeto Temático "Lógicas econômicas práticas espaciais contemporâneas: cidades médias e consumo" (FAPESP, 2012 - 2016), cujos resultados parciais são discutidos neste artigo. Nesse projeto, se define cidades médias como aquelas que desempenham papéis de intermediação no âmbito das redes urbanas das quais são constitutivas (Sposito, 2007), distinguindo-se, portanto, das cidades de porte médio, definidas com base no tamanho populacional. O foco nas cidades médias possibilita uma ampliação do campo analítico dos estudos urbanos, tradicionalmente direcionados aos espaços metropolitanos.

ii Isso não significa que na sociedade capitalista, na qual vivemos, o acesso ao consumo tenha deixado de ser uma necessidade a ser garantida, inclusive como forma de acesso a direitos, como a habitação, e tudo que se produz como importante para habitá-la. O que se discute é a centralidade assumida pelo consumo na vida urbana, como mediação de um número crescente de relações socioespaciais.

iii Cidades médias brasileiras pesquisadas: Marília (207 737 habitantes), Presidente Prudente (203 370 habitantes), São Carlos (213 070 habitantes), São José do Rio Preto (383 558 habitantes) e Ribeirão Preto (603 401 habitantes), no Estado de São Paulo, e Londrina (493 457 habitantes), no Estado do Paraná (Fonte: IBGE [2010] Instituto Brasileiro de Estatística. Rio de Janeiro).

iv Foram os seguintes os procedimentos metodológicos empregados: entrevistas com trabalhadores e representantes das administrações dos shopping centers, observações de campo, pesquisa em jornais, consultas aos sites dos shopping centers e das associações respectivas, contagens de placas dos veículos nos estacionamentos, além da consulta à bibliografia já disponível sobre os shopping centers e cidades pesquisados, e ao IBGE (Instituto Brasileiro de Estatística).

v É radical o caso do Prudenshopping. Foi a Prefeitura Municipal de Presidente Prudente que, proprietária do terreno, iniciou a construção do então denominado Shopping Center Aicás, nos anos 1980. O poder público municipal reproduz a lógica dos incorporadores e demais representantes do mercado imobiliário.

vi O Parque Shopping foi inaugurado em 1986, com o nome de Shopping Americanas.

vii O Prudenshopping foi inaugurado em 1990.

viii O Marília Shopping foi inaugurado em 2000.

ix O Esmeralda Shopping foi inaugurado em 2004.

x O Iguatemi São Carlos foi inaugurado em 1997.

xi O Iguatemi Ribeirão foi inaugurado em 2013.

xii Isso também ocorre com o Marília Shopping, conforme já mencionamos, e com o Iguatemi, inaugurado em maio de 2014, em São José do Rio Preto. 
xiii Para Souza (2010: 52) "o trabalhador é reconhecido como membro útil da sociedade e pode criar uma narrativa de sucesso relativo para sua trajetória pessoal”. O trabalho é, para muitos deles, a verdadeira escola da vida.

xiv Além de continuar a ter o trânsito interrompido, com certa frequência, pelas manobras de caminhões que descarregam nessa área do Prudenshopping.

xv Garrefa (2004: 6) informa que até 1985 o Ribeirão Shopping era servido por apenas uma linha de ônibus, o que interpreta como sinal claro do direcionamento do seu público alvo às classes médias e altas. Indicando as mudanças ocorridas posteriormente, os trabalhadores desse shopping center que entrevistamos valorizaram a sua acessibilidade.

xvi Ainda que exceções tenham sido identificadas, essa é uma característica que pode ser generalizada.

xvii As ampliações são projetos característicos destes espaços nos últimos anos, sendo exceções os casos em que estas não ocorreram e não há previsão de que ocorram. Como exemplos que confirmam a regra, temos o caso do Ribeirão Shopping, que já foi ampliado 8 vezes e informa em seu site sobre os planos para a nona ampliação.

xvii Tomamos a presença de marcas e lojas associadas ao consumo mais elitizado (Gregory, Divina Casa, Pink Lou, por exemplo) como indicativa desse aspecto, ainda que lojas âncoras voltadas aos segmentos de renda média estejam presentes (Riachuelo e Renner).

xix Processo semelhante ocorreu em Ribeirão Preto, quando o anúncio da inauguração do Shopping Iguatemi estimulou a elitização das novas alas pelo Ribeirão Shopping.

xx Dois aspectos, dialeticamente relacionados, devem ser levados em conta quando discutimos a ampliação do consumo: a importância do acesso à habitação, entendida como reconhecimento do "direito à casa própria", dos eletrodomésticos e demais equipamentos relacionados à habitação, aos veículos particulares, como motos e carros, às roupas e calçados etc., embora inseridos no âmbito do consumo e a centralidade adquirida pelo consumo, referenciada na "sociedade do consumo" e expressa na valorização de certos locais de consumo, como é o caso dos shopping centers.

xxi As expressões empregadas pelos entrevistados foram sempre mantidas na transcrição.

xxii Um parque, em relação ao Prudenshopping, uma praça, em relação ao Iguatemi.

xxiii Entrevista coordenada por Arthur Magon Whitacker, em 3/10/2013.

xxiv Padilha (2006: 71) apresenta gráfico com dados de 1981 a 1991, quando o número de shopping centers no Brasil passou de 16 para 90 (Fonte: Abrasce, Associação Brasileira de Shopping Centers, jan. 2003).

xxv Folha de S. Paulo, Caderno Ribeirão Preto, 22/12/1998.

xxvi Entrevista coordenada por Arthur Magon Whitacker, em 21/02/2013.

xxvii Inaugurado em setembro de 2013.

xxviii Inaugurado em maio de 2013.

xxix Inaugurado em maio de 2014.

xxx A Cidade, 30/09/2013.

xxxi 75 milhões de euros (07/07/2016).

xxxii Pode ser que o emprego de uma expressão de língua inglesa, porém, não utilizada nos EUA, shopping center, seja expressiva desse movimento. Conforme informa Padilha (2006: 31), trata-se de "criação brasileira", já que nos países de língua inglesa chama-se shopping mall ou mall, ou ainda shopping centre.

xxxiii Sobre a denúncia dos encobrimentos e inversões que caracterizam o discurso sobre a suposta "desnecessidade do Estado", no âmbito do avanço do neoliberalismo, ver Oliveira (1999).

xxxiv O Parque Shopping possui $15.148 \mathrm{~m}^{2}$ de área bruta locável, segundo seu site.

xxxv O Prudenshopping possui $21.568 \mathrm{~m}^{2}$ de área bruta locável, segundo seu site.

xxxvi Referimo-nos tanto às câmeras de vigilância, como a atuação dos agentes de segurança, e levamos em conta que tais sistemas de segurança são particularmente dinâmicos, caracterizando-se por constantes inovações e mudanças, como é o caso dos novos modelos de câmeras que não permitem a identificação do seu foco e da presença de um agente fardado e armado na entrada do Shopping Iguatemi Ribeirão. 